\title{
The Use of Drugs in Conservation
}

\author{
By A. M. Harthoorn
}

For successful game management and research, immobilising drugs, which make it possible to handle even rhinos and elephants, are essential. The latest drugs, in the discovery and use of which Dr. Harthoorn, of the University College in Nairobi, has played a leading part, make it possible to drug an animal sufficiently for it to be docile but at the same time able to get to its feet and walk unaided. Simple and safe, they have proved their value, for example, in the removal of over 100 square-lipped rhino from Natal without a single casualty due to drug effects.

THE problems associated with the conservation and management of the large wild ungulates in Africa have been highlighted by the controversy over the Tsavo elephant.

One factor that emerges startlingly is our almost total ignorance of the habits, needs, and body processes of the elephant in Kenya. Another is that the older concept of the national parks, as areas where nature must be allowed to take its course whatever happens, has now finally been buried. From a policy that did not permit a single animal to be caught in the parks for marking or measuring, we have now advanced to one of seriously considering the destruction of several thousand of the Tsavo elephants.

In Africa the concept of active research in animal reserves is a comparatively new one. But positive conservation based on scientific research is being adopted throughout Africa. In 1959, faced with the problem of hippo-overpopulation in the Queen Elizabeth National Park, experiments were started, with the wise encouragement of the then Director of Uganda National Parks, Mr. Rennie Bere, on the chemical capture and marking of the hippopotamus; ${ }^{3}$ and also the trial vaccination of buffalo against rinderpest. ${ }^{8}$ The immobilisation of an elephant in the Murchison Falls National Park in 1961 was followed by further work in the Semeliki Valley and experiments on marking for migration studies. ${ }^{10}$

In 1960 preliminary experiments were conducted in the Umfolosi game reserve in Zululand at the request of the far-sighted Director, Colonel Jack Vincent, to ascertain the feasibility of capture and relocation of the rare southern white (square-lipped) rhinoceros, which through careful conservation had increased in numbers in this, its sole remaining location. As a result well over 200 of these magnificent beasts have now been dispersed to new areas by the almost unaided efforts of the game rangers themselves. ${ }^{511}$ About the same time the Hluhluwe Game Reserve in Zululand adopted modern immobilisation techniques for research into their animal problems and for moving surplus populations to farms that wished to restock with game animals. In 1963 the Kruger National Park set up a research project as a 
result of which large numbers of animals which would formerly have been shot, have been captured for disease diagnosis, and a large-scale marking scheme on elephant carried out. ${ }^{12}$ Immobilising techniques have now been adopted among others by the Mlilwane Game Sanctuary in Swaziland, reserves in Zambia and the Ngorongoro Crater in Tanzania.

How far is it necessary to capture animals, to what extent can they be immobilised without pain or danger, and what can be learnt from animal capture in this way?

\section{Kariba Showed the Way}

The need for a method of capturing large animals became fully apparent when black rhinoceros were stranded on the islands in Kariba Lake, and all ordinary methods of removing them failed. The facility with which these marooned animals were removed after immobilisation $^{9}$ was an excellent demonstration of how research and science can help with conservation problems. Much work, however, remained to be done, and the method employed at Kariba was not sufficiently safe for use by game rangers and wardens, neither was it feasible for use on completely unrestricted animals because assistance was necessary soon after the animal went down.

With the object of evolving a safe and generally usable method, primarily for the white rhinoceros problem in Zululand, extensive experimental work was done to find a compound or mixture that conformed to the requirements of large animal capture. It had to have a wide safety margin; it should permit the animal to retain its normal body functions; there had to be an effective and safe antidote, and, lastly, it had to act with rapidity.

At that time it was already evident that the type of drug that produced paralysis was unsuitable for the larger mammals, and that most compounds that were akin to anaesthetics were prone either, if the dosage was light, to make the animal fall repeatedly (often resulting in considerable damage as semi-successful attempts were made to rise), or else lead to prolonged unconsciousness which was likely to result in lung damage, due to depressed respiration or prolonged recumbency, or depression of the circulation resulting in circulatory annoxia and death. The rhinoceros is no exception in this for domestic animals such as horses behave in an identical manner, and much can be learned on the restraint of large animals from veterinary treatises and from tests on domestic animals.

Experiments on several hundred domestic hoofed animals (all of which survived the anaesthesic procedure) indicated that an entirely new effect could be obtained from tranquillisers if these were mixed with synthetic morphine. Even after the latter was reversed with a suitable antagonist, the animal remained in a far more tranquil state than after the adminstration of tranquillisers alone. When large doses of tranquillisers are given to excited animals, they tend to resist the ataraxic effect and frequently become more excited, but seldom 


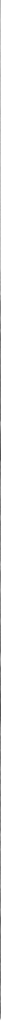

U. de V. Pienaar

\section{AN IMMOBILISED ELEPHANT}

Plate 1: Removing the syringe from a bull elephant after he had come to a halt. 


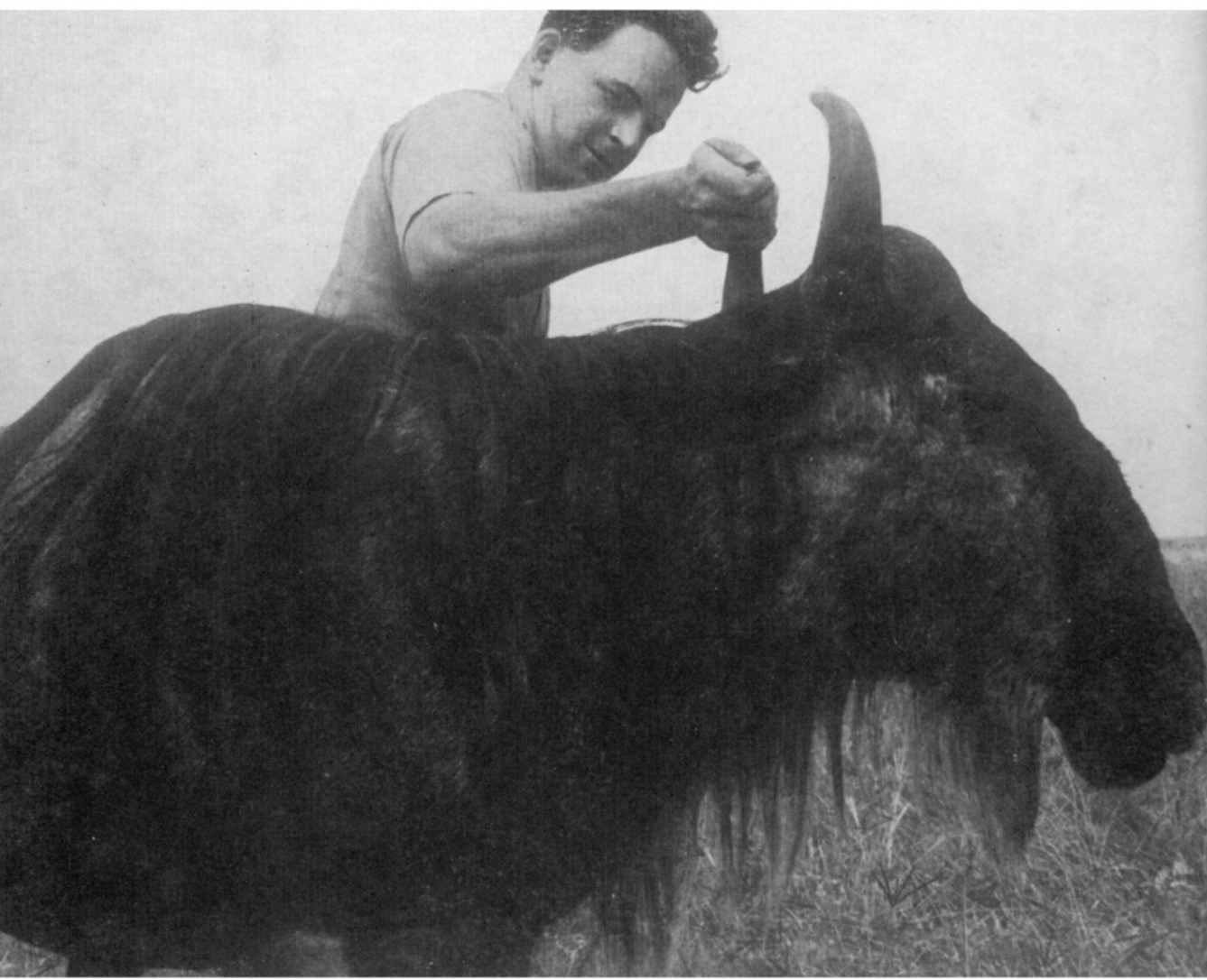

Plate 2: The docility of this captured wildebeest at Kiboko, near Nairobi, is demonstrated by the warden, the late Barry Chappell. All three animals in plates 1-3 were immobilised with the capture drug M.99. 


\section{IMMOBILISING WILDLIFE IN AFRICA}

Photographs by A. M. Harthoorn

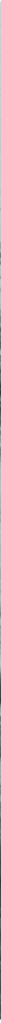

Plate 3: A bull rhinoceros waits patiently. In this state, a rhinoceros will readily enter a crate. 


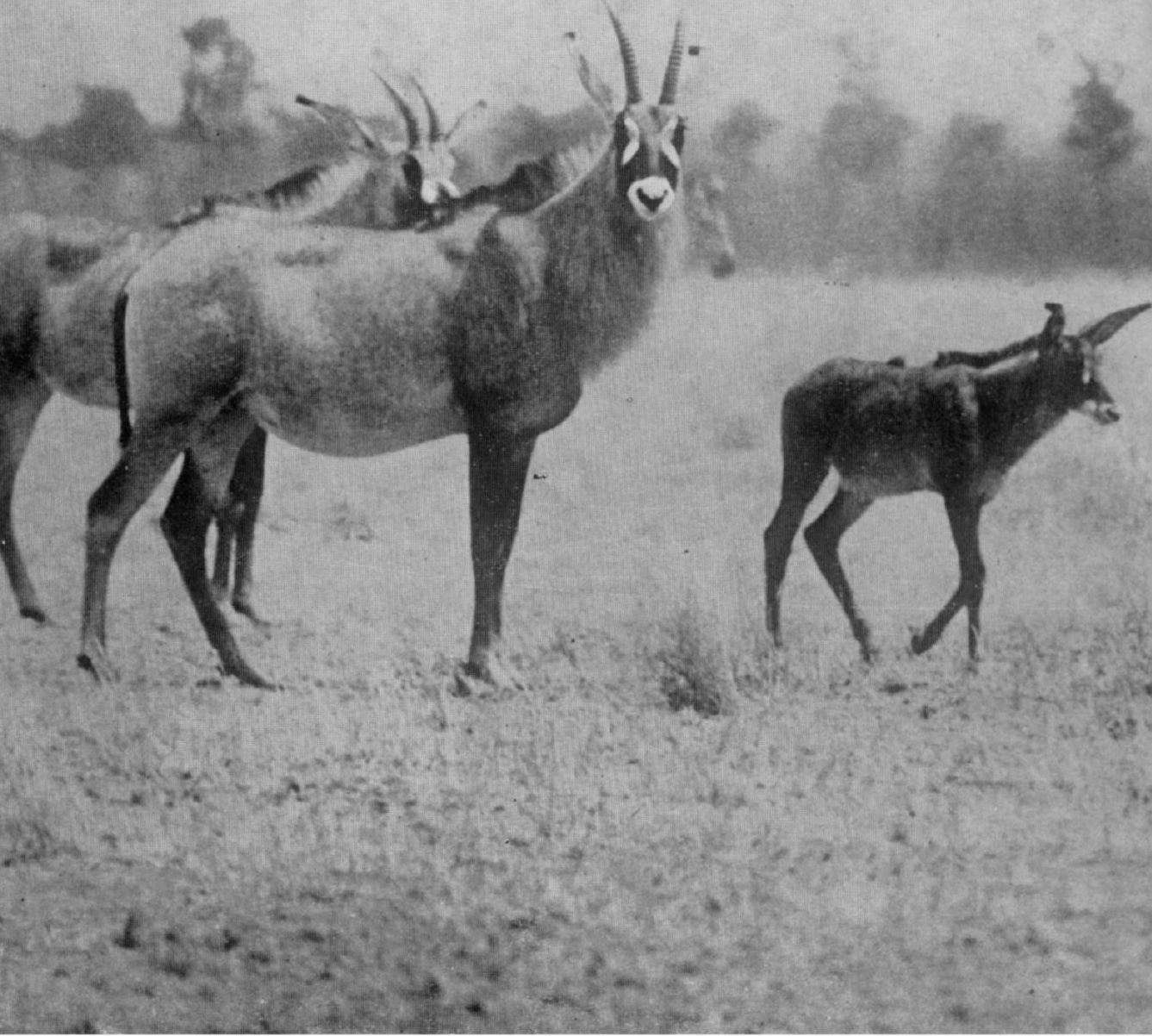

ROAN ANTELOPE IN THE KRUGER NATIONAL PARK

Plate 4: The numbers of roan antelope in the Kruger National Park have dwindled to about 300 . Last year it was planned to capture some, using immobilising drugs, and release them in an area fenced off as a sanctuary in the north of the park where they could be studied and might increase 
tlactable. Morphine or synthetic morphine likewise will usually only result in excitement. When the two are combined however they have a profound quietening effect. So effective is this that animals such as rhinoceros and elephant may be approached and handled while still standing or even walking.

This mixture, to which some scopolamine was added, was completely effective for the capture and relocation of the southern white rhinoceros. It was safe, and a several hundred per cent. overdosage could be given without endangering the animal, compared with only 10 or 20 per cent. with other substances. This overcame one of the greatest problems of rhinoceros capture, that of weight estimation under bush conditions. The affected animals retained their righting reflexes, and in fact often remained standing or walking slowly. Breathing and circulation were largely unaffected even with an overdose. One of the most striking advantages of this mixture was that an effective antidote to the synthetic morphine was available so that its effects could be rapidly reversed. Moreover the reversal could be graduated so that small dosage would just enable the animal to rise, and to start walking, without causing complete wakefulness. Under the effect of partial reversal fully grown rhinoceros, weighing up to 5,000 lbs., could be induced to walk into a crate when it was placed before them. With the use of this mixture well over 100 of the southern white rhinoceros were captured and moved to other locations without one animal dying from drug overdosage or failure to revive from the immobilising dose.

\section{Advantages of the $M$ Compounds}

The rapidity and thus efficiency of capture was still further greatly increased with the use of the recently discovered $M$. series of compounds. ${ }^{2}$ These substances have an activity of up to 10,000 times that of morphine, and very small quantities are sufficient for capturing even the elephant. ${ }^{7}$ One of the M series M.99 has been found suitable for all of the 17 different species on which it has been tried. M.99 is about 1,000 times as active as morphine, but its analgesic or pain relieving effect is much greater. An effective antidote $\mathbf{M . 2 8 5}$ is available in the same series. ${ }^{1}$

The amount of immobilising compound now needed to capture even elephant amounts to only a few drops. It is therefore possible to use and standardise on small projectile syringes which can be fired over reasonably long distances and with considerable accuracy. The same compound can now be used probably for all the ungulates, so that wardens and scientists wishing to immobilise any of the many species in their area need to carry only a few drugs. The safety margin is so large that accurate weight judging is obviated, and the dosage range that can be used sufficiently wide so that mixed batches of animals may be captured as they appear; it used to be necessary to restrict oneself to working with one particular species at a time.

How does this affect conservation? It is now generally accepted 
that effective conservation is only possible when based on a wide knowledge of the territory, plants, and animals which are the object of the conservation practice. Soil, grassland, vegetation and animals all interact to form one ecosystem, and we cannot neglect any major one of these aspects. At present our knowledge of the larger wild animals is probably lagging considerably behind that of plants, soil, and the smaller fauna. To study wild animals, a start may be made by counting and recording their behaviour, but as the investigation progresses it becomes necessary actually to handle the animals. There are certain factors which must be known that are difficult if not impossible to learn from a distance or from observation only; weight gains and growth curves can only be obtained by weighing and measuring; mortality and longevity by marking and observation; movement patterns and migrations by observing marked individuals; disease diagnosis from examination and sampling. For all of these it is necessary to capture the animal.

So far we have dealt with the use of the capture method for study purposes. But to be able to protect animals in a continent where the rapid development of agriculture and growth of populations are constantly impinging on areas where wild animals were once the only inhabitants, humane methods of capturing and relocation are essential. Within very recent times giraffe have been removed from Sebei in Uganda and Rothschild giraffe from Enderbess in Kenya; kob antelope from Lugari; Hunter antelope from the lower Tana; white rhinoceros from West Nile; and roan and other antelope from the Lambwe valley. The rescue of animals in this way will become more frequent, unless we just decide to let them die where they are. The converse obtains when landowners are trying to restock with wild animals, and this happy enterprise should be encouraged by providing animals from areas where they have become locally over-plentiful, at a minimum cost and with the least degree of pain and distress to the animals concerned.

\section{SUMMARY}

To summarise, it may be said that the chemical capture and tranquillisation of African wild hoofed animals has made tremendous strides in the few years since it was first used to study kob antelope in the Semeliki in 1958.4 It is now simple and safe to capture even the largest land mammals. The wider principles involved in caring for the animals during and after immobilisation and transport have been described, ${ }^{6}$ so that mortality from misadventure should also be reduced. The use of the capture method for the study of large animals such as elephant and hippopotamus has now become common, and conservation practice is sounder because it can be based on known facts. On the management side, animals such as rhinoceros that stray from a reserve can now be caught and returned instead of being shot; wounded and trapped animals can be examined to decide their chances of survival, and help given. Regular blood 
sampling of captured animals in reserves indicates the presence of disease and facilitates its control.

REFERENCES

1. BENTLEY, K. W., BOURA, A. L. A., LISTER, R. E. (1965). Compounds containing Morphine-antagonising or Powerful Analgesic Properties. Nature 206: 102-103.

2. BENTLEY, K. W., HARDY, D. G. (1963). New Potent Analgesics in the morphine series. J. Chem. Soc. July. 220.

3. BERE, R. M. (1959). The Hippopotamus Problem Experiment. Oryx V (3): 116-124.

4. BUEOHNER, H. K., HARTHOORN, A. M., and LOOK, J. A. (1960). Immobilising Uganda kob with Succinylcholine Chloride. Canad. Jour. Comp. Med. 24 (No. 11): 317-323

5. HARTHOORN, A. M. (1962). Capture of the white (square-lipped) rhinoceros Ceratotherium simum simum (Burchell) with the use of drug immobilisation technique. Canad. Jour. Comp. Med. 26: 203-208.

6. HARTHOORN, A. M. (1965). Application of pharmacological and physiological principles in restraint of wild animals. Wildl. Monog. (14) 78. (The Wildlife Soc., 3900 Wisconsin Ave., Washington, D.C.)

7. HARTHOORN, A. M., and BLIGH, J. (1965). The use of a new oripavine derivative with potent morphine-like activity for the restraint of hoofed wild animals. Res. Vet. Sci. 6 (3): 290-299.

8. HARTHOORN, A. M., and LOCK, J. A. (1960). A note on the prophylactic vaccination of wild animals. Brit. Vet. Jour. 116 (No. 7): 252-256.

9. HARTHOORN, A. M., and LOCK, J. A. (1960). The rescue of rhinoceroses at Kariba Dam. Oryx V (6); 352-355.

10. HARTHOORN, A. M., and LUCK, C. P. (1962). The handling and marking of the East African elephant Loxodonta africana with the drug immobilisation technique: Second Preliminary Report. Brit. Vet. Jour. 118 : $526-530$.

11. HARTHOORN, A. M., and PLAYER, I. C. (1963). The narcosis of the white rhinoceros. A series of eighteen case histories. Proceedings of the Zoological Congress, Amsterdam.

12. PIENAAR, U, de V. et al. To be published.

\section{WILDLIFE IN A BURMA SANCTUARY}

THE results of the last six annual censuses of the wildlife in the Pidaung sanctuary in Burma, sent to us by U Tun Yin, show that many animals are steadily maintaining the increases they have shown since the catastrophic destruction of the war years. Elephants have gone up from 107 to 175 ; gaur from 88 to 141 ; sambar from 50 to 90 ; hog deer from 27 to 78 , and wild boar from 28 to 83 . These increases, says $U$ Tun Yin, suggest that there is now no poaching in the sanctuary. The two notable exceptions are banteng (tsaine) down from 34 to 8 and tiger down from 7 to 4 . Burma has a programme for declaring 12 wildlife sanctuaries which should be completed by 1970 . In one of these, Tamanthi in the Naga Hills, four rhinoceros have been seen recently. In another, Yegauk, in the Arakan Forest, there are thought to be serow, and tigers and rhinos (Sumatran) have been shot within the last ten years. Such shooting has now been stopped. 